Check for updates

Cite this: RSC Adv., 2017, 7, 19863

Received 27th December 2016

Accepted 14th March 2017

DOI: $10.1039 / c 6 r a 28737 a$

rsc.li/rsc-advances

\section{Fluorescent silver nanoparticle based highly sensitive immunoassay for early detection of HIV infection $\uparrow$}

\author{
Aditya Dileep Kurdekar, (D) a L. A. Avinash Chunduri, (DD a Sai Manohar Chelli, (D) ${ }^{b}$ \\ Mohan Kumar Haleyurgirisetty, (D) ${ }^{c}$ Eswarappa Pradeep Bulagonda, (D) ${ }^{d}$ \\ Jiwen Zheng, ${ }^{\mathrm{e}}$ Indira K. Hewlett ${ }^{\mathrm{c}}$ and Venkataramaniah Kamisetti (D) *a
}

For the first time, we have engineered streptavidin labeled fluorescent silver nanoparticles for their application in immunosensing of biomolecules which will significantly increase sensitivity without compromising the specificity. A computational perspective for understanding the efficiency of the conjugation process is provided as a proof of concept. The fluorescence based sandwich immunoassay was demonstrated to detect HIV-1 p24 antigen in clinical specimens with improved sensitivity and specificity. The detection range of the fluorescent silver nanoparticle-based immunoassay (FSNIA) was found to be between 10 and $1000 \mathrm{pg} \mathrm{mL}^{-1}$ in a linear dose dependent manner. False positives were not observed with plasma samples from healthy adults $\left(\mathrm{HIV}^{-\mathrm{ve}}\right)$, hepatitis $\mathrm{B}\left(\mathrm{HBV}^{+\mathrm{ve}}\right)$ and hepatitis $\mathrm{C}\left(\mathrm{HCV}^{+\mathrm{ve}}\right)$. Plasma samples that were HIV ${ }^{-v e}$ showed no interference with detection of HIV-1 p24 antigen. This technology can be used in resource limited settings and easily adopted for the detection of other pathogen antigens.

\section{Introduction}

Developing countries are witnessing a rise in infectious diseases which are the leading cause of loss of life. ${ }^{1,2}$ Although different diseases such as malaria, tuberculosis, hepatitis, pulmonary infections, to mention a few, are prevalent worldwide, the disease which has caught the attention of the globe due to its severity is Acquired Immune Deficiency Syndrome (AIDS) caused by the Human Immunodeficiency Virus (HIV). Every year nearly 2.2 million people are infected and 1.3 million die from AIDS-related illness. ${ }^{3}$ At the end of 2015 , around 40 million people were living with HIV/AIDS. ${ }^{4}$ AIDS and its related illnesses

${ }^{a}$ Laboratories for Nanoscience and Nanotechnology Research, Department of Physics, Sri Sathya Sai Institute of Higher Learning, Prasanthi Nilayam, Puttaparthi 515134, India.E-mail:vrkamisetti@gmail.com

${ }^{b}$ Department of Chemistry, Sri Sathya Sai Institute of Higher Learning, Prasanthi Nilayam, Puttaparthi 515134, India

${ }^{c}$ Laboratory of Molecular Virology, Center for Biologics Evaluation and Research (CBER), Food and Drug Administration, Silver Spring, MD 20993, USA

${ }^{d}$ Department of Biosciences, Sri Sathya Sai Institute of Higher Learning, Prasanthi Nilayam, Puttaparthi 515134, India

${ }^{e}$ Division of Biology, Chemistry and Material Science, Office of Science and Engineering laboratories, Center for Devices and Radiological Health (CDRH), Food and Drug Administration, Silver Spring, MD 20993, USA

$\dagger$ Electronic supplementary information (ESI) available: Chemistry of synthesis of FSNPs, preliminary computational studies on bioconjugation and components of immunoassay. See DOI: 10.1039/c6ra28737a can affect large part of populations if not diagnosed and treated at the earliest stage.

The viral agent responsible for AIDS (Acquired Immune Deficiency Syndrome), human immunodeficiency virus (HIV), destroys cells of the immune system and progressively impairs the body's ability to defend against other infections and certain cancers. ${ }^{5}$ Antiretrovirals (ARVs) and their use in combination "cocktails" have drastically reduced mortality and morbidity, prolonged life expectancy and improved the quality of lives of infected people, although they have not been able to cure patients of HIV/AIDS. ${ }^{6}$ However, $95 \%$ of people infected with HIV live in developing countries, where the availability and access to these medicines remains unacceptably inadequate and the costs unreasonably exorbitant. Hence, rapid and accurate diagnosis of HIV is pivotal in the management and control of this global outbreak. The diagnostic tools currently available for early detection of HIV often require advanced and elaborate facilities which restrict their application in resource limited settings. Currently available diagnostic assays need further improvement for early detection and this can be achieved using nanoparticles for signal amplification coupled with sensitive and specific antibodies. Thus, the current need is rapid, sensitive and specific diagnostics at point of care which are capable of rapid identification and characterization of the disease allowing patients to get immediate treatment for effective clinical outcomes.

When it comes to detection of HIV, there are a wide variety and range of biomarkers related to HIV infection, which can 
even predict the progress of HIV infection to AIDS. ${ }^{7}$ Although HIV antibody tests are the most appropriate for identifying the infection, they are insufficient due to the time the antibodies take to manifest in the plasma. ${ }^{8}$ Hence, alternate efficient technologies are required for accurate diagnosis for monitoring response to therapy, and to effectively predict disease outcome. Virus isolation through viral culture, nucleic acid detection techniques to detect viral RNA, ${ }^{\mathbf{9}}$ and tests to detect p24 antigen ${ }^{\mathbf{1 0}}$ are commonly used clinical methods to identify virus or viral components in blood early, and confirm an infection. While, these methods are highly specific, each has limitations and their use is restricted to highly specific testing situation depending on the resources available. Although tests for viral RNA detection have been introduced recently, their requirements of complex instrumentation and well-trained personnel makes them unsuitable for resource limited settings. ${ }^{\mathbf{1 1}}$

The p24 antigen tests stand out amongst all other tests as it is one of the earliest protein biomarkers to appear in blood after infection. The HIV-1 capsid (core) p24 is detected much earlier than antibodies during an acute HIV infection. ${ }^{12} \mathrm{~A}$ major advantage that p24 testing offers is that it is highly specific for HIV infection. Testing for p24 can be of value in: early detection of HIV infection, ${ }^{\mathbf{1 3}}$ screening blood donor samples, ${ }^{\mathbf{1 4}, \mathbf{1 5}}$ diagnosing infection in the newborn, ${ }^{\mathbf{1 6 , 1 7}}$ and monitoring antiviral therapy. ${ }^{18}$

There are many sensitive detection platforms for HIV p24 detection but user friendly point-of-care rapid test platforms are an unmet need. The most widely used test format is the enzymelinked immunosorbent assays (ELISAs) ${ }^{19}$ which requires separate wells in the assay for each analyte to be detected and use of an enzyme which can be unstable making it less convenient. Since it is frequently necessary or helpful to detect several biomarkers simultaneously, conventional ELISAs make the process time consuming. ${ }^{20}$ Current ELISA methods are further limited by problems common to the use of enzymes, contamination of the substrate solution and the need to read the micro well shortly after completion of the enzyme/substrate reaction. ${ }^{21}$

The use of fluorescence-linked immunoassays gives advantages over ELISAs such as increased sensitivity, a larger dynamic range and greater stability of reagents. ${ }^{22,23}$ Fluorescence methods may also be multiplexed, thereby using lower volumes of reagents and decreasing the assay time. ${ }^{24}$ The ability to spectroscopically detect multiple analytes in a single well assay is not without its challenges. These include cross reactivity of antibodies, ${ }^{25}$ the need for discrete spectral bands which do not overlap too closely, ${ }^{26}$ and the possibility of interaction between the fluorophores. The use of fluorescent nanoparticles removes some of these challenges which has prompted the application of fluorescent nanoparticles as immunoassay labels.

Noble metal nanoparticles which are generally clusters of 5100 atoms shielded by capping agents, ${ }^{27}$ are of particular interest for their exceptional properties like high tunability of their optical spectra and high surface to volume ratios allowing a higher surface area for specific bio-functionalization. ${ }^{28-30}$ In the field of protein detection, noble metal nanoparticles have played a key role in the development of highly sensitive detection platforms for rapid identification of disease biomarkers. ${ }^{31,32}$

Silver nanoparticles (AgNPs), have been extensively studied for their application in biosensing based on their photoluminescence, surface plasmon resonance, optical scattering, and labelling features. ${ }^{334}$ These nanoparticles are being explored for other sensing applications in composites and assembled nanostructures for their synergistic properties. ${ }^{35,36}$ AgNPs have also been exploited for the development of protocols involving metal enhanced fluorescence based detection, surface-enhanced Raman scattering (SERS) and in combination with gold to form bimetallic NPs which can either be alloys or core shell nanoparticles. ${ }^{37,38}$

Fluorescent silver nanoparticles (FSNPs) are emerging functional materials which have generated significant interest in the field of bioimaging and biosensing. ${ }^{39,40}$ These particles can interact with light as they have discreet energy levels due to quantum confinement, ${ }^{\mathbf{4 1}}$ allowing intense light absorption and emission. ${ }^{42,43}$ These optical properties along with superior biocompatibility, brightness and photostability have led to their application as fluorescent biolabels. ${ }^{\mathbf{4 4 , 4 5}}$ Additionally, these FSNPs can have application as sensitive probes, as their fluorescence emission is a function of their interaction with the organic scaffold. ${ }^{46-48}$

Combining the efficiency of FSNPs in biosensing with the current need for sensitive detection of biomarkers, we report the development of a versatile fluorescent silver nanoparticle immunoassay (FSNIA). The FSNPs bioconjugated to streptavidin can be used with biotin labeled antibodies or antigens for detection of target antigen or antibodies. The conjugation and functioning of FSNPs was interpreted using computational modeling. A mechanistic interpretation of the bio-conjugation was sought for immunosensing applications for which in silico studies were performed using various computational methods to explain the thermodynamics of these processes. In this regard, the energetics of individual steps was evaluated to elucidate the process of the conjugation observed. FSNIA was then employed for the detection of HIV. HIV-1 p24 was chosen as the model analyte as it is the biomarker for early detection of HIV. The results in this study can help in development of a multiplexed screening protocol based on FSNPs which could be potentially beneficial in clinical settings and in the control and prevention of the spread of AIDS.

\section{Experimental}

\subsection{Chemicals and reagents}

Glutathione (Himedia), silver nitrate (Sigma), hydrazine hydrate (Thermo Scientific), 1-ethyl-3-(3-dimethylaminopropyl) carbodiimide, (Thermo Scientific, USA), $N$-hydroxysuccinimide (Thermo Scientific, USA), streptavidin (Scripps Lab, USA), casein block buffer (Thermo Scientific, USA), anti-HIV-1 p24 antibody (Prospec, USA), HIV-1 p24 antigen (Virogen, USA), biotinylated HIV-1 p24 detector antibody (Perkin-Elmer, USA). Phosphate buffer saline (100 mM, pH-7.2) and carbonate bicarbonate buffer (500 mM, pH-9.5) were prepared by following established procedures. Centrifugal spin columns 
(10, 30, $100 \mathrm{kDa})$ were purchased from GE Health Care, UK. Double distilled water was used for performing all the experiments. Plasma samples from patients and healthy individuals were obtained from the Sri Sathya Sai Institute of Higher Medical Sciences, Prasanthigram, India, (study id-SSSIHL/IEC/ PSN/BS/2012/01). The details of the samples were coded and tested in a blinded manner. Samples were confirmed to be positive or negative using fourth generation Microlisa HIV Ag + Ab Elisa kit (J. Mitra \& Co. Pvt. Ltd.).

\subsection{Synthesis of fluorescent silver nanoparticles}

Fluorescent silver nanoparticles (FSNPs) were prepared following the process of chemical reduction using hydrazine hydrate as the reducing agent. ${ }^{49} 5 \mathrm{~mL}$ aqueous solution of $2 \mathrm{mM}$ glutathione was mixed (with vigorous stirring) with $5 \mathrm{~mL}$ aqueous solution of $1 \mathrm{mM}$ silver nitrate till a milky white acidic solution was obtained. The acidic gel was brought to neutral $\mathrm{pH}$ by adding $400 \mu \mathrm{L}$ of sodium hydroxide (1 M) until a clear solution was formed. Following the formation of a clear solution, the rate of stirring was reduced and after 5 minutes, $500 \mu \mathrm{L}$ of hydrazine hydrate was added. The solution was now stirred for 10 hours till it turned pale yellow. The resulting solution was filtered to remove any large particulates using a nitrocellulose membrane. The filtered solution was lyophilized and stored at $4{ }^{\circ} \mathrm{C}$ for further characterization and immunoassay experiments.

\subsection{Characterization of the FSNPs}

The morphology and size of the FSNP dispersion was characterized using a Jeol 1400 TEM at $80 \mathrm{kV}$ and LIBRA 200 High Resolution Transmission Electron Microscope operated at 200 $\mathrm{kV}$, respectively. The FSNPs were drop casted on the copper grid and vacuum dried before imaging. Total 514 particles were analyzed using Image $\mathrm{J}$ to determine the size distribution of particles. The optical characterization experiments and measurements were carried out using Shimadzu 2450 UV-Vis spectrophotometer and Spectramax M5 microplate reader. To obtain the absorbance and fluorescence spectra, the samples were accordingly diluted. FTIR spectra were obtained using Thermo Scientific Nicolet 10 FT-IR spectrometer on the potassium bromide $(\mathrm{KBr})$ pellet.

\subsection{Bioconjugation of FSNPs with streptavidin}

The bioconjugation of the above purified FSNPs was carried out using the EDC-NHS coupling protocol. ${ }^{50} 10 \mathrm{mg}$ of nanoparticles were dispersed in $10 \mathrm{mM}$ phosphate buffer $(\mathrm{pH}=7.4)$ and were washed in centrifugal spin columns. Nanoparticles were dispersed in Phosphate Buffered Saline (PBS) and the solution was sonicated with a tip sonicator for $30 \mathrm{~s}$. The activation of carboxyl groups was carried out by mixing the FSNPs with $10 \mathrm{mmol} \mathrm{L}^{-1}$ of EDC and $10 \mathrm{mmol} \mathrm{L}^{-1}$ NHS in PBS buffer for $30 \mathrm{~min}$. These activated particles were washed once with wash buffer. To this solution, $50 \mu \mathrm{L}$ solution of $1 \mathrm{mg} \mathrm{mL}{ }^{-1}$ streptavidin dissolved in carbonate bicarbonate buffer $(\mathrm{pH}=9.0)$ was added. The above prepared solution was incubated at room temperature for $3 \mathrm{~h}$ following which the streptavidin conjugated nanoparticles were washed 5 times with the wash buffer.
In order to gain a deeper mechanistic understanding of the bio-conjugation for immunosensing applications, in silico studies were performed using various computational methods to rationalize the thermodynamics of these processes. In this regard, the energetics of the individual steps was evaluated to elucidate the process of the conjugation observed.

2.4.1 Energetics of the conjugation step. The molecules involved in the studies were constructed in ChemSketch and were optimized in MOE (Molecular Operating Environment) using the MMFX99 force field. ${ }^{51}$ In the bio-conjugation protocol, the individual reactants and products were optimized and their net energies for every individual stage of the process were calculated. Further, to enunciate the role of silver nanoparticles in this particular conjugation, the glutathione molecule (GSH) was modified with the thiol group replaced by $\mathrm{S}-\mathrm{Ag}$ ( $1 \mathrm{Ag}[\mathrm{GSH}])$, S-6 Ag(6 Ag[GSH]), and lastly S-31 Ag (31 Ag[GSH]).

2.4.2 Conjugation of the nanoparticle to the protein. Given that the bio-conjugation is primarily the interaction of the GSH-NHS intermediate with streptavidin, we evaluated the role of $\mathrm{Ag}$ in this interaction. In this regard, the molecular docking studies were carried out using Hex 8.0.0 where the interactions between the different $\mathrm{Ag}-\mathrm{GSH}$ ligands and streptavidin were generated as HEX scores that are an indicator for the binding affinity. ${ }^{52}$

2.4.3 Interaction of biotin with the conjugated protein. The deterministic step that allows the sensing of p24 by the fluorescent probe is based on the interaction between the FSNP conjugated streptavidin and biotinylated detector antibody. Hence, we assessed the effect of conjugation on consequent binding to biotin. The 1, 6 and $31 \mathrm{Ag}[\mathrm{GSH}]$ systems conjugated to streptavidin were consequently studied for their binding affinity unto biotin using HEX 8.0.0. This was eventually compared to the control, which is reaction in the absence of glutathione conjugation.

\subsection{Fluorescence polarization}

The fluorescence polarization experiments were carried out in order to ascertain whether the process of bioconjugation has produced conjugated nanoparticles. The difference in the fluorescence polarization value is the indicator of size of the bioconjugated molecule, which increases after conjugation. ${ }^{53}$ The excitation and emission wavelengths were chosen as $401 \mathrm{~nm}$ and $716 \mathrm{~nm}$ respectively. The fluorescence polarization value was calculated from the formula given by eqn (1),

$$
\mathrm{FP}=\frac{I_{\|}-G \times I_{\perp}}{I_{\|}+G \times I_{\perp}}
$$

where, FP is fluorescence polarization, $I_{\|}$is the parallel polarized emission, $I_{\perp}$ is the perpendicularly polarized emission, $G$ is the correction factor which is evaluated for the sensitivity of the instrument.

The $I_{\|}$and $I_{\perp}$ were measured in the fluorescence polarization mode by Spectramax M5 plate reader and substituted in the above formula to obtain the FP ratio. Conjugation is confirmed by the higher magnitude of fluorescence polarization for the conjugated FSNPs compared to the unconjugated FSNPs. 


\subsection{Fluorescent silver nanoparticle immunoassay (FSNIA)} for detection of HIV-1 p24 antigen

2.6.1 Immunoassay protocol. A capture antibody concentration of $1 \mu \mathrm{g} \mathrm{mL}^{-1}$ was prepared by diluting the stock solution with carbonate-bicarbonate buffer $(100 \mathrm{mM}, \mathrm{pH} 9.6) .55 \mu \mathrm{L}$ of this capture antibody solution was coated on to the Nunc maxisorp fluorescence microplates and the plates were incubated for 24 hours at $4{ }^{\circ} \mathrm{C}$. After the incubation period, the plates were washed with wash buffer 5 times followed by washing the wells with $300 \mu \mathrm{L}$ of casein blocking buffer and incubated for 30 minutes at $37^{\circ} \mathrm{C}$. The casein block buffer will ensure that all the non-specific absorption sites are blocked and it will also reduce the background signal. In the next step, different concentrations of HIV-1 p24 antigen diluted in blocking buffer were added to each well and incubated at $37{ }^{\circ} \mathrm{C}$ with shaking for 1 hour. Following the incubation step, all the wells were washed 5 times with wash buffer. In the subsequent step, $100 \mu \mathrm{L}$ of biotinylated detector antibody was added to each well and incubated at $37{ }^{\circ} \mathrm{C}$ for 30 minutes. This step completes the formation of this antibody-antigen-antibody sandwich complex to which $100 \mu \mathrm{L}$ of streptavidin conjugated FSNPs $\left(1.5 \mathrm{mg} \mathrm{mL}^{-1}\right)$ were added and left to incubate again for 30 minutes at $37^{\circ} \mathrm{C}$ with shaking. A final washing step was performed 5 times with PBST buffer to avoid non-specific interactions and reduce the background noise. Finally, the microplate was placed in the Spectramax microplate reader and the fluorescent signal intensities from the sandwich immunocomplexes were measured in a time resolved mode with excitation at $401 \mathrm{~nm}$ and emission at $716 \mathrm{~nm}$. All experiments were performed in triplicate. The fluorescence cut off value was derived using the mean of the fluorescence signal intensities of six negative controls plus 2 times their standard deviation (SD). Samples with signal-to-cut off (S/CO) ratios equal to or greater than 2 were considered positive for HIV-1 p24. A schematic representation of the detection of p 24 antigen by FSNIA is shown in the Scheme 1.

2.6.2 Control experiment. To study the effects of interference of proteins, a control experiment was performed wherein Bovine Serum Albumin (BSA) was taken as an interfering protein and FSNIA was examined for interference. Five different concentrations of BSA were taken: $0.1 \mu \mathrm{g} \mathrm{mL} \mathrm{m}^{-1}, 0.5 \mu \mathrm{g} \mathrm{mL}{ }^{-1}, 1.0$ $\mu \mathrm{g} \mathrm{mL} \mathrm{L}^{-1}, 5.0 \mu \mathrm{g} \mathrm{mL}^{-1}$ and $10.0 \mu \mathrm{g} \mathrm{mL}^{-1}$, and its effects on the fluorescence signal were observed for a fixed p24 concentration

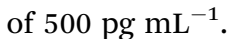

In addition to interference of a protein, studies were also carried out to see the interference effect of coexisting viruses. For our study, hepatitis $\mathrm{C}$ virus (HCV) was chosen as an interfering virus as it is a common co-infection in HIV patients. To study the effect of the presence of $\mathrm{HCV}$ as an interfering agent in the immunoassay, the HCV positive plasma sample was diluted 10, 20, 50 and 100 times. $500 \mathrm{pg} \mathrm{mL}^{-1}$ of p24 antigen was spiked in all the solution including the undiluted plasma sample. The immunoassay was carried out on the spiked samples.

\subsection{HIV detection in blood plasma samples}

2.7.1 Preparing plasma samples. The plasma samples were tested with commercial kits for HIV antigen and antibody. $2 \mu \mathrm{L}$ of tested plasma was diluted in $188 \mu \mathrm{L}$ casein block buffer and $10 \mu \mathrm{L}$ of $10 \%$ aqueous solution of Triton X-100 was added.

2.7.2 HIV-1 p24 spiked plasma samples. To check the efficacy of our detection system, the first step involved testing HIV negative plasma samples spiked with known concentrations of p24 antigen. These spiked plasma samples were serially diluted with PBS solution to obtain the desired concentrations. The samples were then subjected to FSNIA and the percent recovery for each sample was calculated by the formula as described by eqn (2).

$$
\text { Recovery } \%=\frac{\text { measured concentration }}{\text { actual concentration }} \times 100
$$

It is necessary to test the performance of the assay with clinical samples in order to evaluate its applicability to clinical studies. To validate the assay, FSNIA was evaluated using $50 \mathrm{HIV}$ positive and $50 \mathrm{HIV}$ negative clinical samples. These samples were prepared using the procedure described before. The cross reactivity was also evaluated with $10 \mathrm{HBV}$ positive/HIV negative and $10 \mathrm{HCV}$ positive/HIV negative plasma samples.

\section{Results and discussion}

\subsection{Morphological characterization of fluorescent silver nanoparticles}

The synthesis of FSNPs is discussed in Section S1† in ESM. The size and morphology of the silver nanoparticles was confirmed by TEM imaging. The TEM images as seen in Fig. 1 show the particle size to be $15.4 \pm 3.7 \mathrm{~nm}$ of spherical morphology. The HRTEM confirmed the interplanar spacing to be $0.237 \mathrm{~nm}$ which is in accordance with the literature. ${ }^{54}$ The nanoparticles were found to be polycrystalline which also is a reported observation. ${ }^{55}$

\subsection{Optical spectral characteristics of fluorescent silver nanoparticles}

UV-Vis spectroscopy and photoluminescence spectroscopy studies were used to study the optical properties of the FSNPs. As illustrated in Fig. 2, the absorption spectra revealed a broad peak in the range of 370-450 nm with the peak maximum at $401 \mathrm{~nm}$. On being subjected to UV light (365 nm), a red emission was observed which is visible to naked eyes. A broad emission centered at $716 \mathrm{~nm}$ was observed in the emission spectrum with an excitation wavelength peak at $360 \mathrm{~nm}$. This emission can be attributed to hybrid states which are formed due to the interaction of glutathione and silver at their interface. ${ }^{56}$

In order to understand the surface functionalization on the FSNPs, FTIR studies were carried out (Fig. 3a). The most important feature of the FTIR spectra obtained was the missing peak at $2510 \mathrm{~cm}^{-1}$ which is the characteristic absorption peak for $\mathrm{S}-\mathrm{H}$ indicating that the $\mathrm{S}-\mathrm{H}$ group is not freely available in the FSNPs. This suggests that glutathione caps the silver nanoparticles through the thiol from cysteine. ${ }^{57}$ The stretching vibration band which is the characteristic peak of carboxylic group was found to have shifted slightly to a lower wavenumber of $1602 \mathrm{~cm}^{-1}$ which can be attributed to weak interaction 


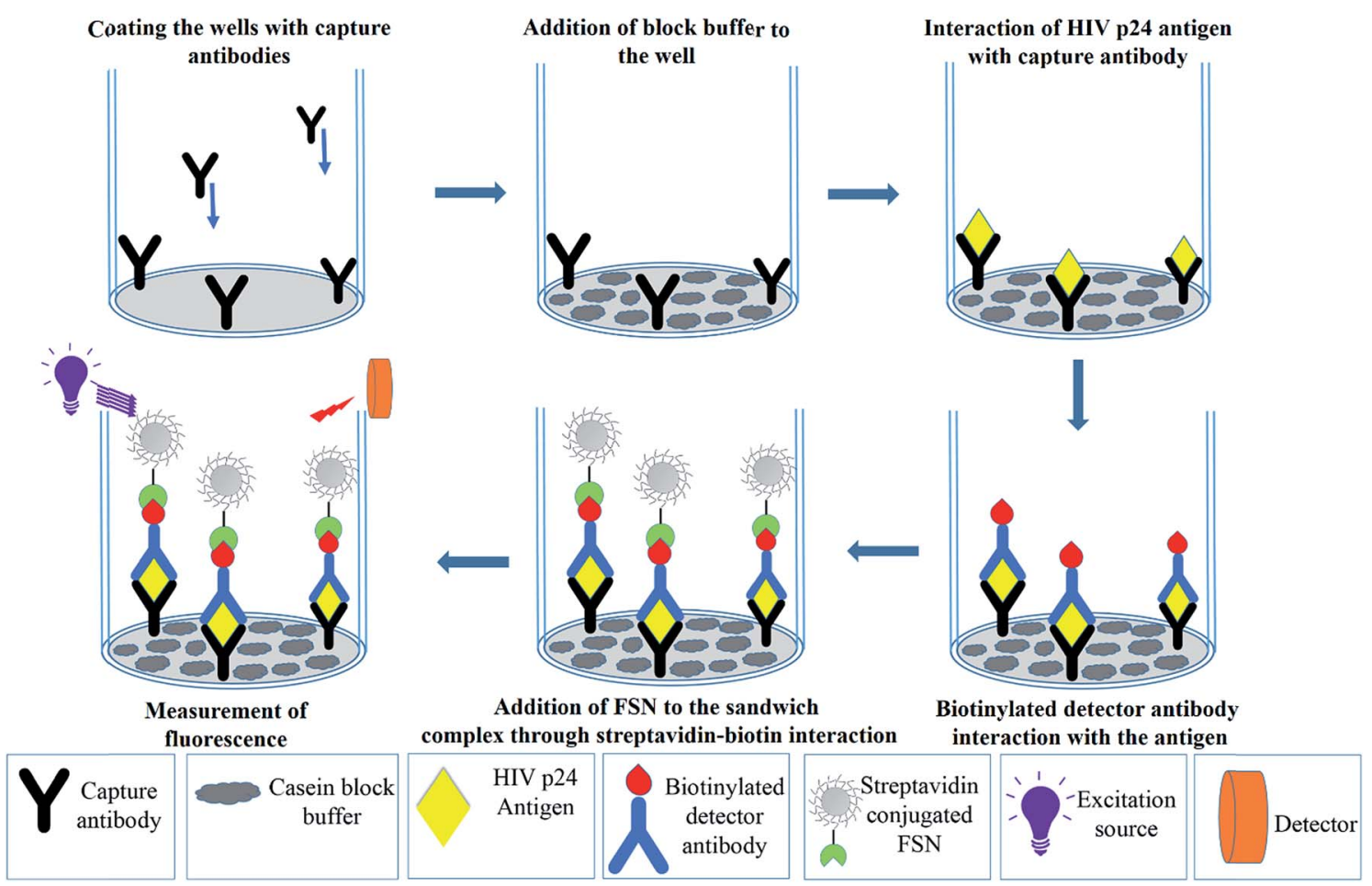

Scheme 1 Schematic illustration of steps involved in FSNIA.

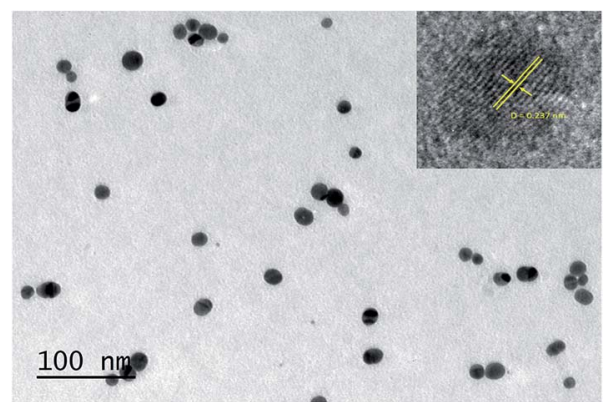

Fig. 1 TEM image of FSNPs which indicates the size of the FSNPs to be around $15.4 \pm 3.7 \mathrm{~nm}$. The inset shows the HRTEM image of FSNPs which indicate a $d$ spacing of $0.237 \mathrm{~nm}$.

between the negatively charged $\mathrm{COO}^{-}$and electropositive silver core as depicted in Fig. $3 \mathrm{~b} .^{58}$ The peak at $1356 \mathrm{~cm}^{-1}$ is an indicator of deformation and vibration features of $\mathrm{C}-\mathrm{N}$ linkage which is predominant in this tripeptide. Meanwhile, the 1093 $\mathrm{cm}^{-1}$ peak is due to the vibration band of $\mathrm{C}-\mathrm{O}$. The peaks at $2974 \mathrm{~cm}^{-1}$ and $1464 \mathrm{~cm}^{-1}$ can be ascribed to the stretching and bending vibrations of aliphatic $\mathrm{C}-\mathrm{H}$ group in glutathione. ${ }^{59}$ The 1010-880 and $850-740$ bands are the out of plane vibration bands of $\mathrm{C}-\mathrm{H}$ and $\mathrm{N}-\mathrm{H}$ group which are typically formed by interaction of the silver nanoparticle with $\mathrm{GSH} .{ }^{60}$

\subsection{Bioconjugation of fluorescent silver nanoparticles to streptavidin}

Streptavidin conjugation to FSNPs was performed to make them specific for biomolecular recognition of biotin labeled antibodies.

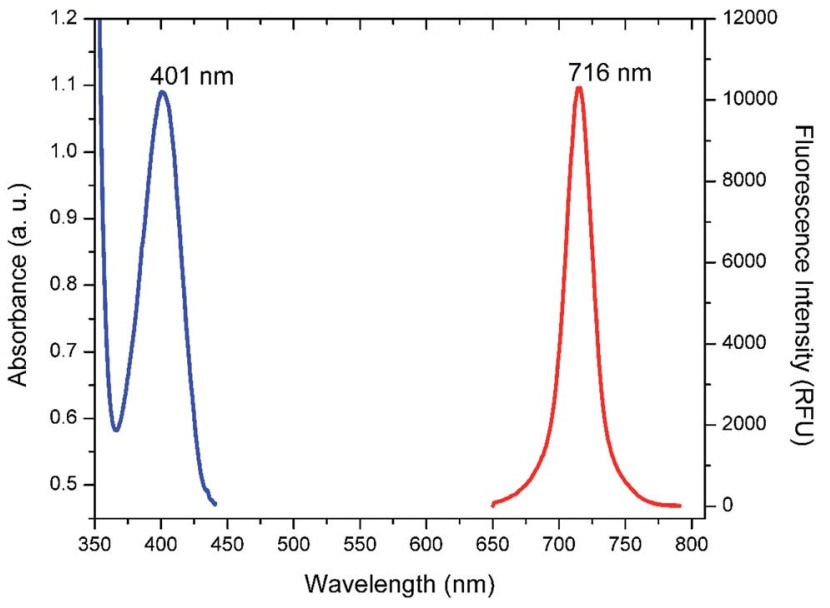

Fig. 2 UV-Vis absorbance and fluorescence emission spectra of FSNPs. The blue peak is the absorbance spectra while the red one is fluorescence spectra of FSNPs.

Since it is difficult to directly conjugate a protein to a nanoparticle with high efficiency, an intermediary coupling protocol was chosen. Now, the most well established and versatile methods that exist for conjugating or crosslinking a moiety to carboxylic acid are based on carbodiimide compounds. Since the medium is aqueous, 1-ethyl-3-(3-dimethylaminopropyl) carbodiimide (EDC) was chosen. $N$-hydroxysuccinimide (NHS) is an essential part of EDC based coupling protocols, whose purpose is to enhance the coupling efficiency and create amine-reactive intermediates which are stable. EDC helps in coupling of NHS to carboxyls forming an NHS ester which is more stable than the $O$-acylisourea 

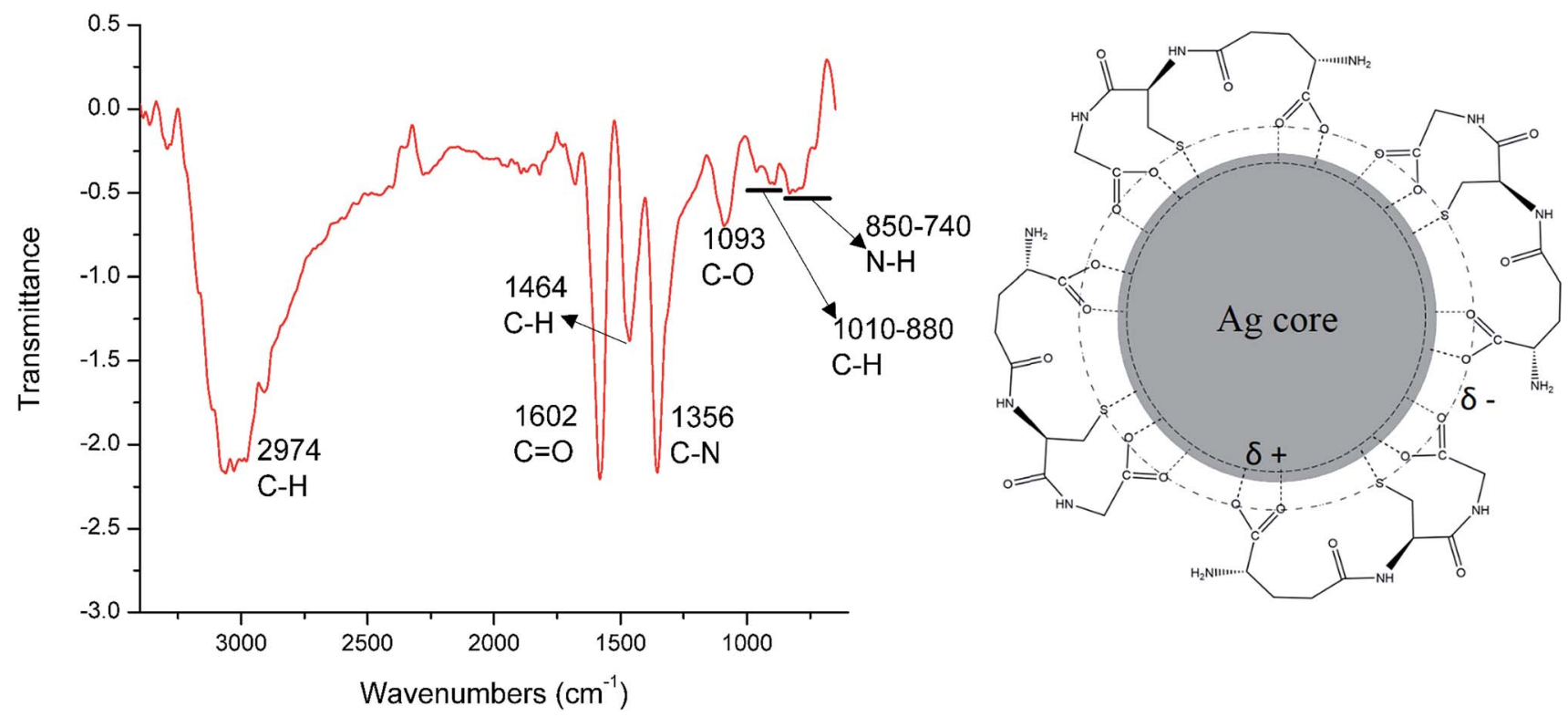

Fig. 3 (a) FTIR spectrum of FSNPs (b) interaction between the silver core and glutathione molecules.

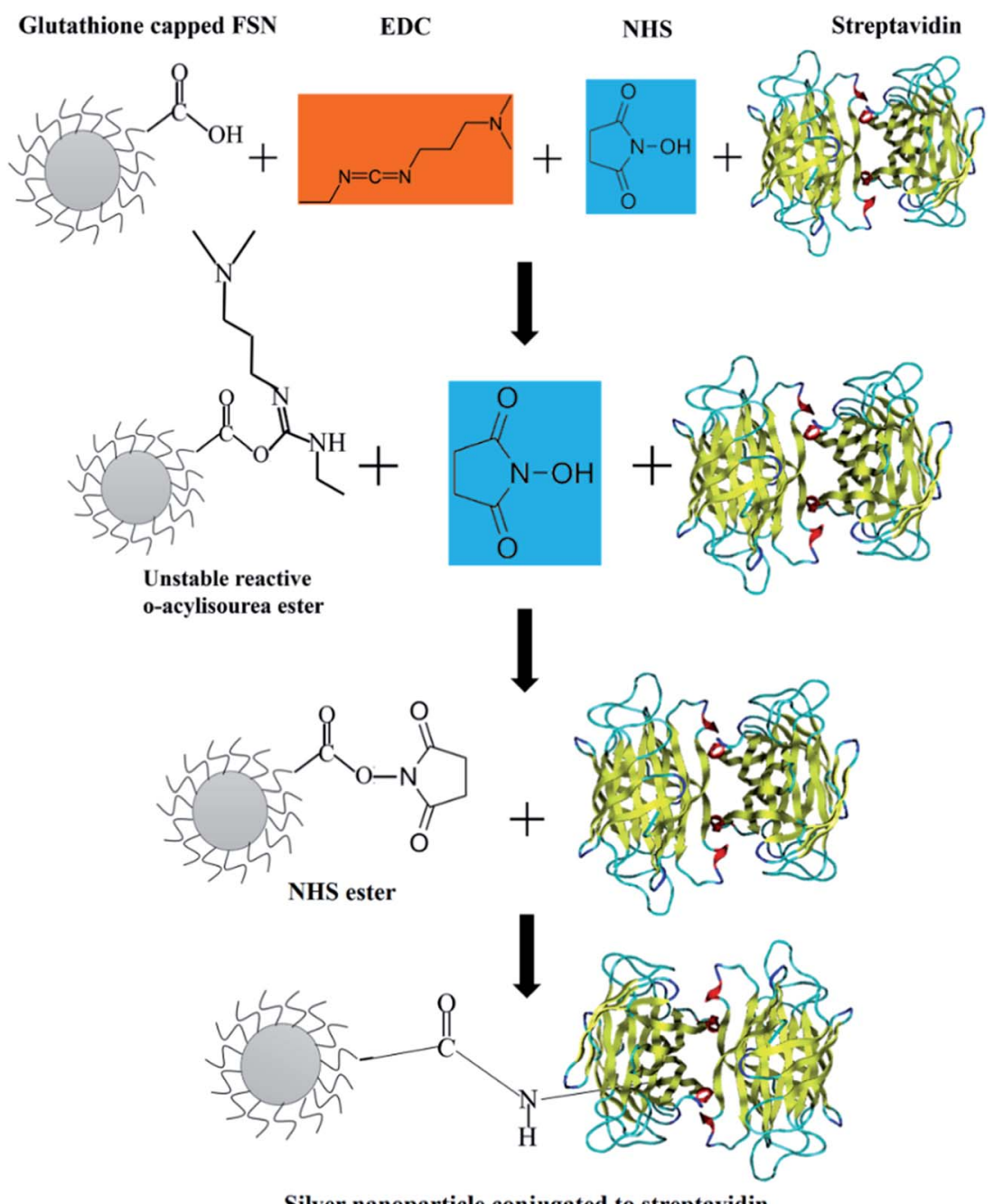

Silver nanoparticle conjugated to streptavidin

Scheme 2 Schematic illustration of conjugation of FSNPs to streptavidin through EDC-NHS. 
intermediate. ${ }^{\mathbf{6 1}}$ It also permits bioconjugation to primary amines at physiological $\mathrm{pH}$. The coupling reaction was carried out in PBS whose $\mathrm{pH}$ is 7.4, which is compatible with the bioconjugation chemistry. ${ }^{62}$

A schematic representation of the conjugation protocol is presented in Scheme 2. The first step of this reaction is the interaction between the glutathione from the FSNPS with EDC. It results in the formation of an unstable $o$-acylisourea intermediate. This intermediate reacts with NHS and forms an amine reactive NHS ester which is considerably more stable than the $o$-acylisourea intermediate. The final addition to this reaction mixture is the protein, streptavidin. The $\mathrm{NH}_{2}$ from the amino acids in streptavidin reacts with the amine reactive NHS ester and results in formation of an amide bond between

Table 1 Hex scores for different ligand systems binding to streptavidin

\begin{tabular}{ll}
\hline Molecule & $\begin{array}{l}\text { Hex 8.0.0 } \\
\text { score }\end{array}$ \\
\hline $\mathrm{GSH}$ & -262.1 \\
$\mathrm{Ag}[\mathrm{GSH}]$ & -260 \\
$6 \mathrm{Ag}[\mathrm{GSH}]$ & -324.42 \\
$31 \mathrm{Ag}[\mathrm{GSH}]$ & -380.03
\end{tabular}

carboxylic group of glutathione and amine group from streptavidin.

3.3.1 Computational modelling of interaction between FSNPs with streptavidin. The preliminary calculations on efficiency of conjugation are presented as Section S2 $\uparrow$ in ESM. Computational studies on bio-conjugation of the EDC-NHS coupled molecules to streptavidin in HEX has given significant understanding as to the nature of conjugation of all silver glutathione systems to the protein. All the ligand interactions were found to have a negative HEX score which indicated the favorable nature of binding for all ligands. From Table 1, it is clear that out of all the ligands, $31 \mathrm{Ag}[\mathrm{GSH}]$ has the best binding affinity. Interestingly, the binding affinity for $1 \mathrm{Ag}[\mathrm{GSH}]$ was found to be lower than glutathione which could be understood from the interaction profile which indicates that the number of interactions which the $\mathrm{Ag}[\mathrm{GSH}]$ has is lesser than GSH interacting with the protein (Fig. 4). These interactions stabilize the ligands docking with the protein and thus we obtain a more negative Hex score. Similarly the interactions for $6 \mathrm{Ag}[\mathrm{GSH}]$ and $31 \mathrm{Ag}[\mathrm{GSH}]$ are even higher which clearly explains the more negative hex score and higher binding affinity of $31 \mathrm{Ag}[\mathrm{GSH}]$. Thus, we see a trend of increasing conjugation efficiency with increasing number of particles.

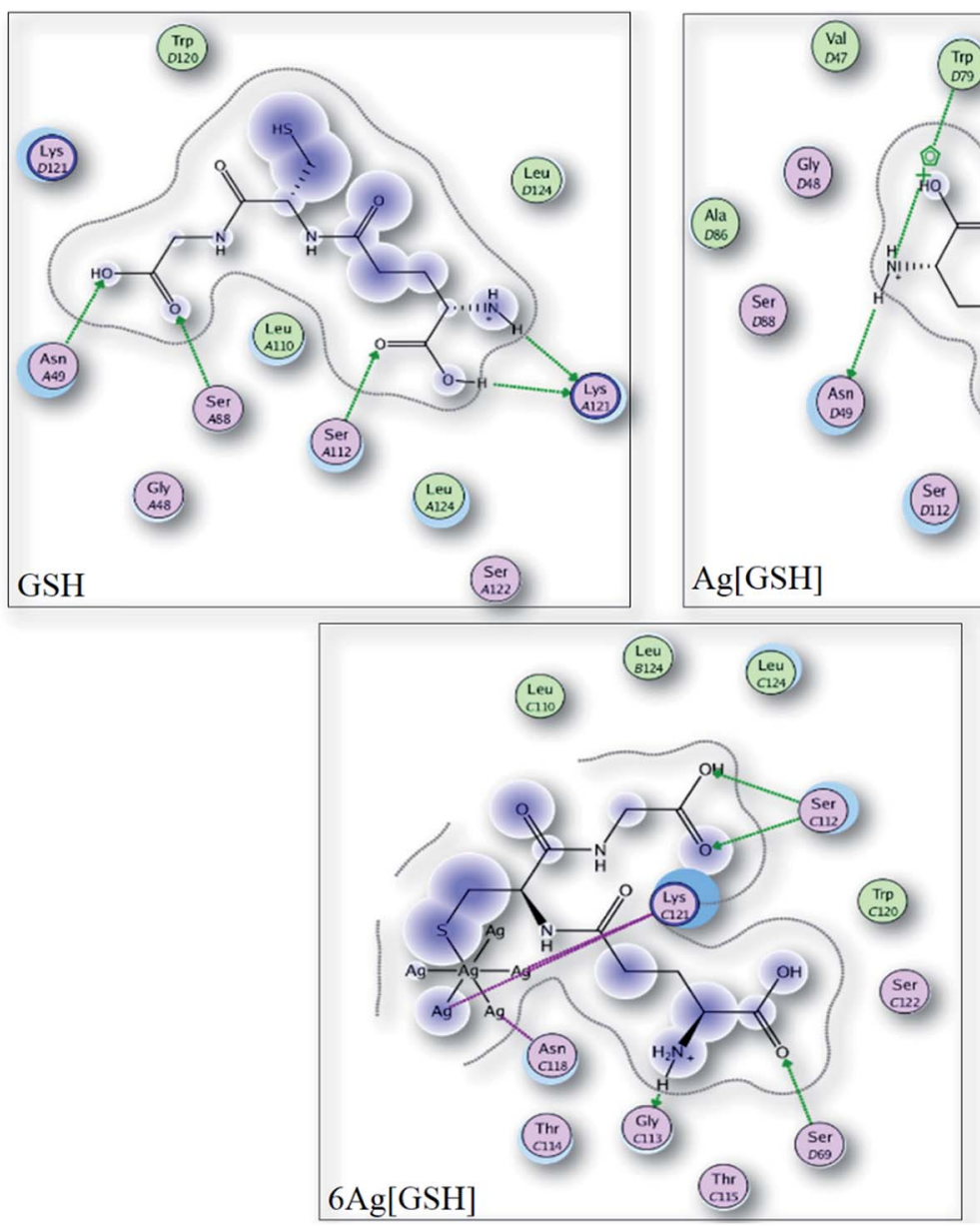

Fig. 4 Interactions of (a) glutathione (b) 1 Ag-glutathione and (c) 6 Ag-glutathione with the streptavidin as determined by HEX docking. 
3.3.2 Computational modelling of conjugated streptavidinbiotin interaction. The preliminary calculations have been presented in Section S $3 \uparrow$ in ESM. The detection step, which involves the streptavidin-biotin interaction was studied for all the Ag-GSH systems as to determine the effect of bioconjugation on the interaction. Based on the biotin docking studies, the calculated binding affinities are presented in Table 2. While the most stable configuration is $1 \mathrm{Ag}[\mathrm{GSH}]$, the second most stable system is GSH followed by the $31 \mathrm{Ag}[\mathrm{GSH}]$ and next comes the $6 \mathrm{Ag}[\mathrm{GSH}]$. The minimal difference between the HEX score indicates that the 31 atoms conjugated system can also interact with biotin with the same affinity as the other systems.

The slight destabilization of protein explains the difference in binding affinity. The tradeoff between the stabilization of the $\mathrm{Ag}-\mathrm{GSH}$ (by interaction between $\mathrm{Ag}$ and the amino acids) with destabilization of protein due to the steric hindrance plays crucial role in this protein biotin interaction. While 31 atom system may sterically destabilize the protein but the silver amino acid interactions counteract the destabilization allowing a successful interaction of the conjugated protein with biotin. Thus, the highlight of this study is that the bioconjugation process still allows the protein to interact with biotin with significant binding affinity which is important for immunoassay applications.

\subsection{Fluorescence polarization studies}

The confirmation of conjugation was obtained through the fluorescence polarization studies which were performed on the Spectramax M5 plate reader in the fluorescence polarization mode. The correction factor $(G)$ of the plate reader was calculated to be 1 . The results of the FP are depicted in the Table 3 .

The higher value of FP of the streptavidin conjugated FSNPs in comparison to unconjugated FSNPs confirms the bioconjugation of FSNPs to streptavidin. To understand this, we need to have a look at the correlation between fluorescence polarization and size of the fluorophores. The smaller size of unconjugated particles leads to their movement in solutions that results in depolarization of the incident plane polarized

Table 2 Hex scores for interaction of conjugated protein with biotin for different ligand systems

\begin{tabular}{ll}
\hline Binding moieties & HEX score \\
\hline GSH-streptavidin-biotin & -224.5 \\
$\mathrm{Ag}[\mathrm{GSH}]$-streptavidin-biotin & -233.3 \\
$6 \mathrm{Ag}[\mathrm{GSH}]$-streptavidin-biotin & -221.1 \\
$31 \mathrm{Ag}[\mathrm{GSH}]-$ streptavidin-biotin & -223.6
\end{tabular}

Table 3 Comparison of fluorescence polarization value of the unconjugated FSNPs with the conjugated FSNPs

\begin{tabular}{|c|c|c|c|c|}
\hline Sample & $I_{\|}$ & $I_{\perp}$ & $\mathrm{FP}=$ & $\frac{I_{\|}-G \times I_{\perp}}{I_{\|}+G \times I_{\perp}}$ \\
\hline Unconjugated FSNPs & 93 & 76 & 0.105 & \\
\hline Streptavidin conjugated FSNPs & 138 & 104 & 0.140 & \\
\hline
\end{tabular}

excitation energy thus leading to very low polarization value. ${ }^{\mathbf{6 3 , 6 4}}$ However, the conjugation of FSNPs to streptavidin reduces the motion of the particle due to an increase in the size and volume of the particles. This reduces the rotation of particles which causes the excitation energy and the transmitted energy to be in the same state of polarization expressed as a higher magnitude of polarization value. ${ }^{65}$ This manifests as a higher value of FP for the conjugated particle than that of the unconjugated particle.

\subsection{Results of fluorescent silver nanoparticle immunoassay (FSNIA) for the detection of HIV-1 p24}

HIV-1 p24 antigen is the target viral protein in this study because of its abundance in the early stages of HIV infection when antibody concentrations are low and not detectable. This in turn helps in early detection of the disease which can allow better management of the disease and antiretroviral treatment. In this study, we adapted p24 antigen to assess the performance of FSNIA. In order to test the sensitivity of the FSNIA, we decided to test its limits in detecting p24 antigen. The immunoassay involved the formation of antibody-antigen-antibody sandwich complex where in the detection step involved interaction between the biotinylated detector antibody and streptavidin conjugated FSNPs. The detection process makes use of the strong non-covalent chemistry between biotin and streptavidin which immobilizes the fluorophore to the sandwich complex. When illuminated by excitation energy, the fluorophore emits and the signal intensity is proportional to the amount of streptavidin conjugated FSNPs. The amount of streptavidin conjugated FSNPs are in turn proportional to amount of p24 present. Thus, the signal intensity is directly proportional to the concentration of p24 present in the sample. The fluorescence signal intensity is then measured using a SpectraMax M5 microplate reader. A calibration curve for the purified HIV-1 p24 antigen is plotted with the measured data.

3.5.1 Calibration curve. The FSNIA was found to work efficiently in detecting p24 in the linear working range of $10 \mathrm{pg}$ $\mathrm{mL}^{-1}$ to $1000 \mathrm{pg} \mathrm{mL} \mathrm{m}^{-1}$ as observed in Fig. 5a and b. This dynamic range observed here is very useful for detecting p24 antigen concentrations within days after exposure upto 3 weeks, after which, due to seroconversion, the antigen becomes undetectable. ${ }^{66}$ Thus, this range is very significant in the early detection of the infection. A linear relation between the concentration of p24 and signal intensity was observed for the whole range tested. A very clear difference was observed between the measured signal intensity and the blank intensity until $10 \mathrm{pg} \mathrm{mL}^{-1}$ of the $\mathrm{p} 24$, lower concentration than this could not be distinguished from background. Thus, our FSNIA could

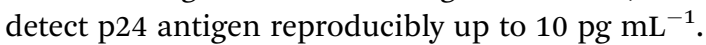

3.5.2 Analytical performance of FSNIA. Statistically, for FSNIA the fluorescence cut-off value was obtained using the sum of the means of the signal intensity of negative controls plus 2 times their standard deviation (SD) and was found to be 33.283 RFUs. $^{67}$ The limit of detection was found out to be $8.2 \mathrm{pg}$ $\mathrm{mL}^{-1}$ for the dynamic range of $10-1000 \mathrm{pg} \mathrm{mL}^{-1}$ for a signal to cutoff value of $2: 1$, which was chosen as the measure for 

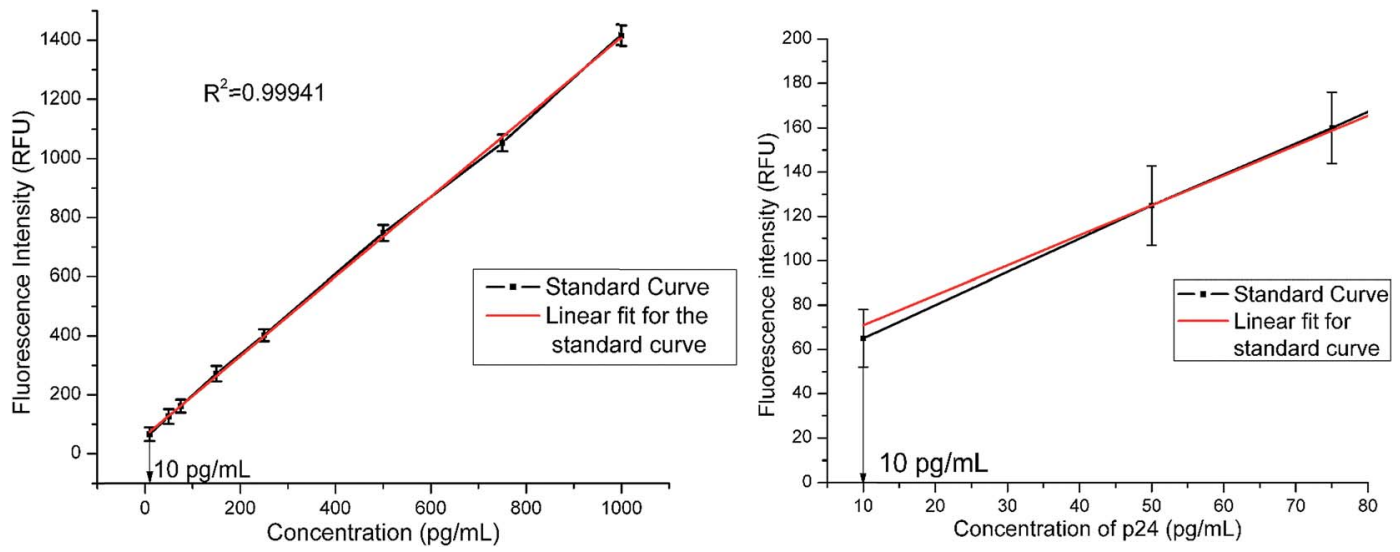

Fig. 5 (a) Plot of the calibration curve for FSNIA. The red line indicates the fitting curve obtained by linear regression. (b) Standard plot of FSNIA with resolved axis that points to the lower detection limit of FSNIA.

determining positive samples. ${ }^{68}$ The equation of linear correlation was determined to be

$$
\mathrm{FI}=1.34 \times C+55.38
$$

where FI is fluorescence intensity, $C$ is the concentration of p24.

We obtained very good linear correlation in eqn (3) between the concentrations of $\mathrm{p} 24$ and the fluorescence signal intensity in FSNIA with a high correlation coefficient of $R^{2}=0.99941$. This also suggests that FSNIA is a linear dose response assay. In this paper, we report that this FSNIA could achieve an analytical sensitivity at the picogram level which is comparable to the sensitivity levels achieved with conventional colorimetric ELISA (Table 4).

\subsection{Control experiment}

3.6.1 Effect of presence of an interfering protein. The presence of various proteins and other biomolecules necessitated the study of interference from other proteins on the immunoassay.

Table 4 Comparison of sensitivities of detection techniques based on application of silver nanoparticles used for sensing various analytes

\begin{tabular}{llll}
\hline Method & Analyte & $\begin{array}{l}\text { Concentration } \\
\left(\mathrm{pg} \mathrm{mL}^{-1}\right)\end{array}$ & Ref. \\
\hline $\begin{array}{l}\text { Conventional } \\
\text { ELISA }\end{array}$ & p24 antigen & $10-15$ & 70 \\
EIS & Arsenic & 13 & 71 \\
CLMI & Cysteine & 25 & 72 \\
Multiarray-LSPR & Proteins & 100 & 73 \\
Colorimetric & Cancer biomarker & 30 & 74 \\
& cyclin A & & \\
SPRI & IgG & 7 & 75 \\
RLS & Alpha feto protein & 40 & 76 \\
Lab on chip & Staphylococcal & 100 & 77 \\
& enterotoxin B & & 78 \\
Lab on disc & Anti-hepatitis & 510 & 79 \\
& B virus & & Present study \\
SERS & DNA & 50 & \\
FSNIA & HIV-1 p24 & 10 &
\end{tabular}

With BSA as a model protein, it was observed that the BSA has no effect on the signal intensities in the immunoassay. Fig. 6 clearly illustrates that there is barely any alteration in the signal strength with increasing BSA concentration. This further reinforces the stability of the immunoassay protocol.

3.6.2 Effect of coexistent viruses. To further analyze the extent of specificity and cross reactivity of FSNIA, HCV positive plasma samples were spiked with HIV-1 p24 antigen, a fixed concentration of $500 \mathrm{pg} \mathrm{mL} \mathrm{m}^{-1}$. The results as depicted in Fig. 7 indicate that there is no perceivable effect on the fluorescence signal from the HCV virions suggesting that FSNIA is an exceptionally specific and stable testing protocol.

\subsection{Optimization of FSNIA}

The optimization of immunoassay was performed by optimizing two critical parameters in the immunoassay: capture antibody concentration and FSN-SA concentration.

\subsubsection{Capture antibody}

3.7.1.1 Optimization of the capture antibody concentration. A very important parameter that affects the sensitivity of the immunoassay is the concentration of capture antibodies. There is an optimal concentration of capture antibody at

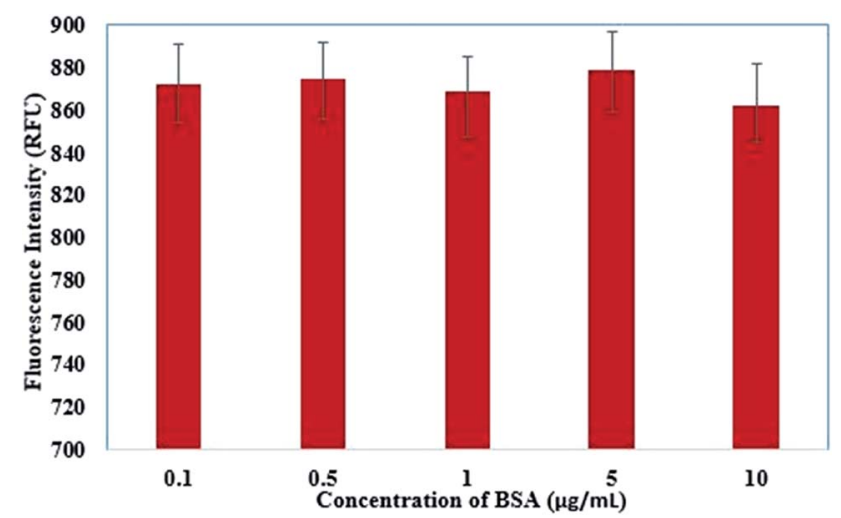

Fig. 6 Plot of fluorescence intensities for $500 \mathrm{pg} \mathrm{mL}^{-1}$ p24 antigen in samples with varying concentration of BSA. 


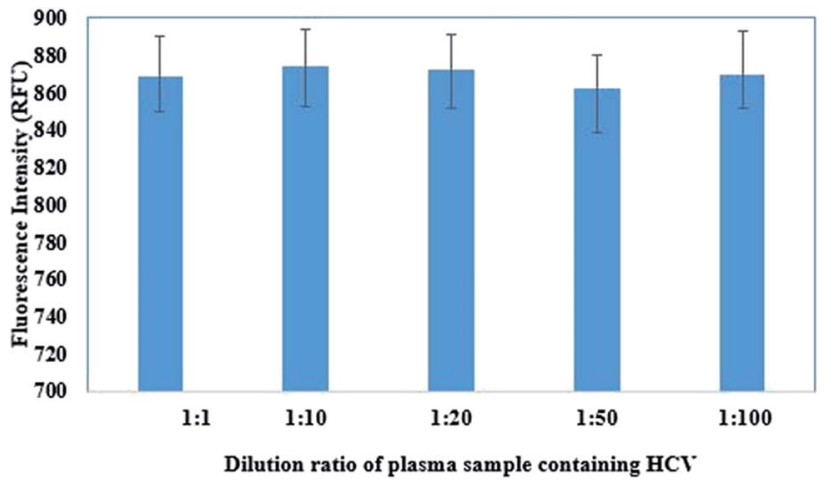

Fig. 7 Effect of dilution of HIV-1 p24 spiked HCV sample on fluorescence intensity from FSNIA.

which the signal will be highest; at higher concentrations the background signal can also be higher and concentrations below this, the signal will be weaker. ${ }^{69}$ Optimization of concentration of capture antibody required for the assay was done by testing different concentrations of $0.5 \mu \mathrm{g} \mathrm{mL} \mathrm{L}^{-1}, 0.8 \mu \mathrm{g}$ $\mathrm{mL}^{-1}, 1 \mu \mathrm{g} \mathrm{mL} \mathrm{m}^{-1}$ and $2 \mu \mathrm{g} \mathrm{mL} \mathrm{m}^{-1}$. As shown in Fig. 8, for $0.5 \mu \mathrm{g}$ $\mathrm{mL}^{-1}$ and $0.8 \mu \mathrm{g} \mathrm{mL} \mathrm{m}^{-1}$ the signal response was poor and there was no good correlation between the observed signal and antibody concentration. However, at $1 \mu \mathrm{g} \mathrm{mL}{ }^{-1}$, there was a strong response observed. For concentration higher than 1 $\mu \mathrm{g} \mathrm{mL}^{-1}$, there was no change in the response which can be attributed to the saturation of the detection area with capture antibodies at $1 \mu \mathrm{g} \mathrm{mL} L^{-1}$. As a result, $1 \mu \mathrm{g} \mathrm{mL} L^{-1}$ was chosen as the optimal concentration of capture antibody for further experimentation.

3.7.2 FSN-SA. The streptavidin conjugated FSNPs are the fluorescent particles which are used in this detection process. The streptavidin-biotin interaction allows FSNPs to indirectly interact with the detector antibody and when the FSNPs are excited with the excitation signal, the intensity of the output

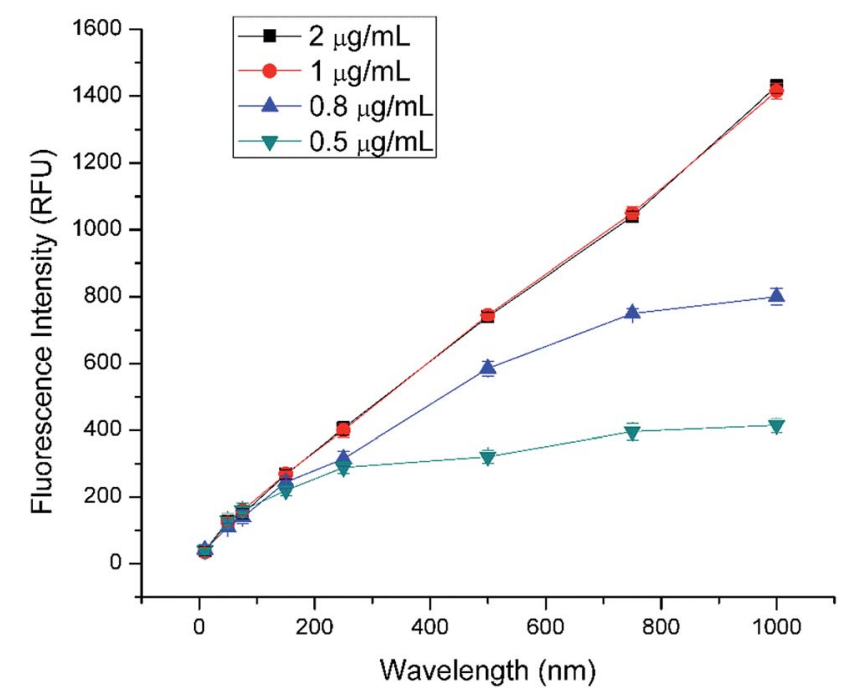

Fig. 8 Effect of varying concentration of capture antibodies on fluorescence intensities in FSNIA.

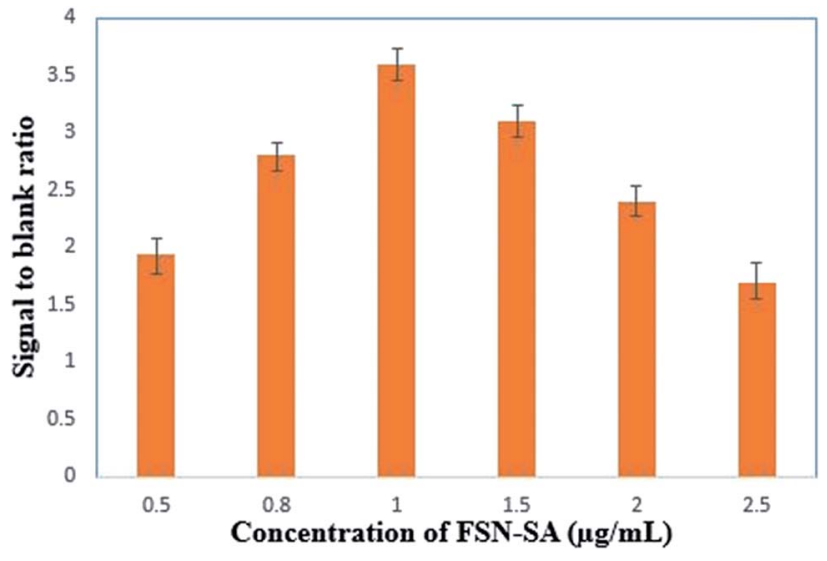

Fig. 9 Effect of varying concentration of FSN-SA on signal to blank ratio of fixed concentration of $250 \mathrm{pg} \mathrm{mL}^{-1}$ of p24 in FSNIA.

(fluorescence) signal is an indicator of the amount of antigen present. The signal was read with a spectrophotometer. The linear correlation between the fluorescence intensity and the antigen concentration allows us to plot the calibration curve.

3.7.2.1 Optimization of the streptavidin conjugated FSNPS concentration. Concentration of FSN- SA greatly affects the performance of the assay. Six concentrations of FSN-SA: $0.5 \mathrm{mg}$ $\mathrm{mL}^{-1}, 0.8 \mathrm{mg} \mathrm{mL}^{-1}, 1 \mathrm{mg} \mathrm{mL} \mathrm{m}^{-1}, 1.5 \mathrm{mg} \mathrm{mL}^{-1}, 2 \mathrm{mg} \mathrm{mL}^{-1}$, $2.5 \mathrm{mg} \mathrm{mL}^{-1}$, were taken to study its effect on the signal to blank ratio ( $\mathrm{S} / \mathrm{B}$ ratio) in FSNIA. The blank measurements were obtained by performing the immunoassay in absence of the antigen. The optimization of FSN-SA was carried out by measuring and calculating the $\mathrm{S} / \mathrm{B}$ ratio for concentration of 250 pg mL ${ }^{-1}$ of p24 antigen. It is clear from Fig. 9 that no linear relation exists between the FSN-SA concentration and the S/B ratio. At a concentration $1.5 \mathrm{mg} \mathrm{mL}^{-1}$ of FSN-SA the highest $\mathrm{S} /$ B ratio was observed. With an increase in FSN-SA concentration beyond the optimal concentration the blank intensity was also observed to have increased rapidly when compared to the signal intensity. This increase of blank intensity could be attributed to the non-specific absorption of FSN-SA.

\subsection{Precision and recovery rate of the assay}

Our next objective was to study the applicability of FSNIA in real world scenario by testing human plasma samples. The first step

Table 5 The recovery percentages calculated for each of the concentration

\begin{tabular}{llcl}
\hline S. no & $\begin{array}{l}\text { p24 spiked } \\
\left(\mathrm{pg} \mathrm{mL} \mathrm{mL}^{-1}\right)\end{array}$ & $\begin{array}{l}\text { p24 detected } \\
\left.(\mathrm{pg} \mathrm{mL})^{-1}\right)\end{array}$ & \multicolumn{1}{l}{$\begin{array}{l}\text { Recovery } \\
(\%)\end{array}$} \\
\hline 1 & 10 & $9.2 \pm 0.5$ & $92.0 \pm 5.0$ \\
2 & 50 & $47.6 \pm 2.1$ & $95.2 \pm 4.2$ \\
3 & 75 & $71.3 \pm 4.5$ & $95.0 \pm 4.3$ \\
4 & 150 & $145.1 \pm 5.8$ & $96.7 \pm 3.9$ \\
5 & 250 & $242.7 \pm 6.5$ & $97.1 \pm 2.7$ \\
6 & 500 & $482.3 \pm 15.9$ & $96.4 \pm 3.3$ \\
7 & 750 & $740.0 \pm 19.6$ & $98.6 \pm 2.8$ \\
8 & 1000 & $989.2 \pm 39.4$ & $98.9 \pm 3.9$
\end{tabular}


was to determine the sensitivity of the assay which was done by testing 50 plasma samples of healthy individuals. All the samples tested negative and no false positives were observed. The next step was to further evaluate the analytical sensitivity of the assay and this was done by taking known concentrations of p24 antigen and spiking the HIV negative plasma samples collected from healthy individuals (HIV negative sample). The plasma samples were diluted 100 times which in turn reduced the sample amount required for analysis. To the diluted plasma sample, purified p24 antigen concentrations of 10, 50, 150, 250 and $500 \mathrm{pg} \mathrm{mL}{ }^{-1}$ were added. All experiments were conducted in triplicate and the concentration was calculated by taking the average signal response and comparing it with the standard curve (Fig. 5a). It is clear from Table 5 that the concentrations of p24 antigen calculated from the results of FSNIA are comparable to the actual amounts spiked into sample. Thus FSNIA can quantitatively determine the concentration of HIV-1 p24 antigen in clinical plasma samples.

\subsection{Clinical serum sample analysis}

To further establish the effectiveness of FSNIA, we tested the specificity of FSNIA using samples from infected individuals (HIV positive samples). Plasma samples were diluted 100 times prior to the analysis. We tested $50 \mathrm{HIV}$ positive samples (which were confirmed by 3 rd and 4 th generation commercial ELISA kits) using FSNIA and no false negatives were observed. To test FSNIA for cross reactivity we also evaluated the assay with 10 HBV positive/HIV negative and $10 \mathrm{HCV}$ positive/HIV negative
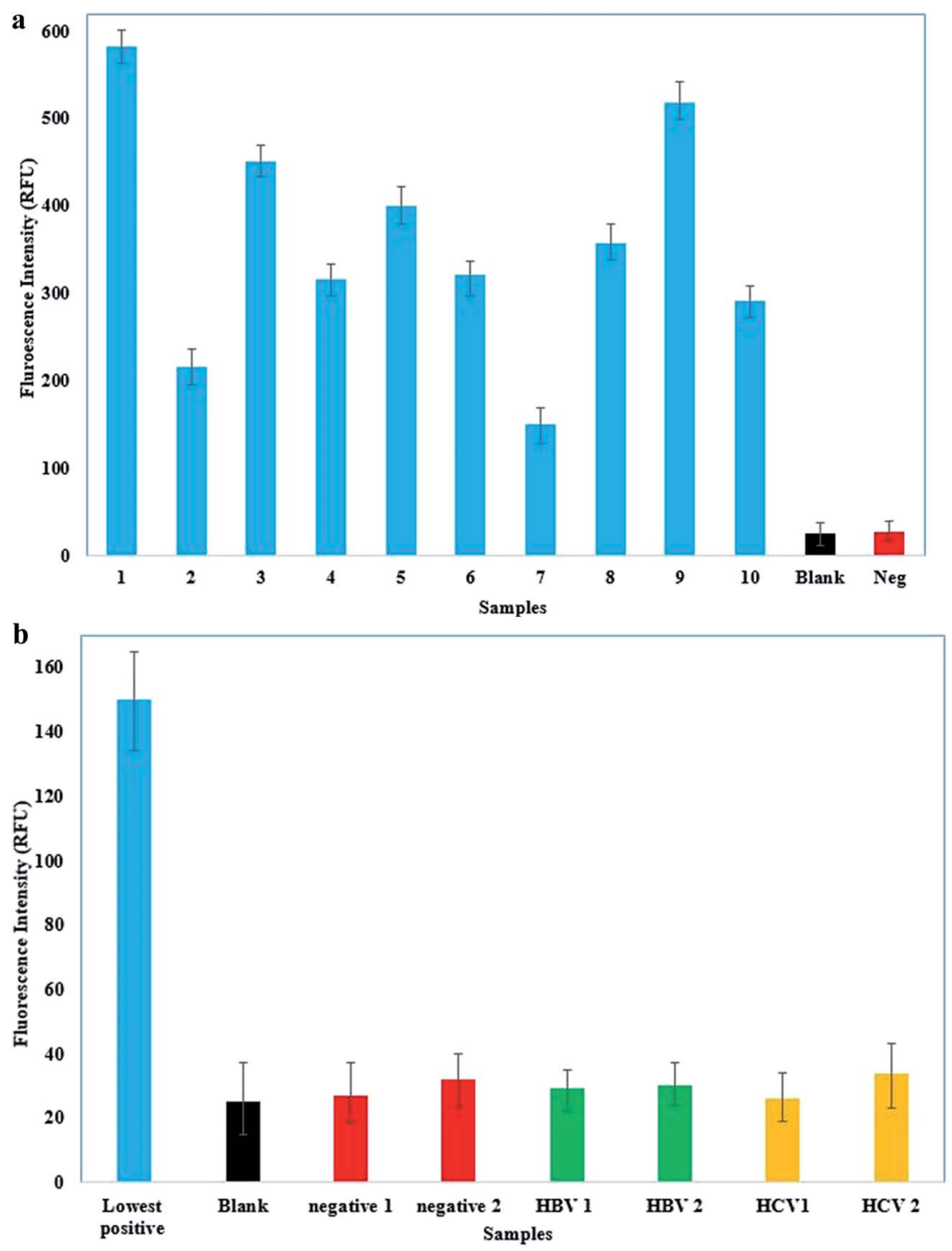

Fig. 10 (a) Results of FSNIA for 10 HIV positive samples chosen at random compared with the results from blank and the intensity of a HIVnegative sample. The blue, black and red bars indicate the intensity of the positive, blank and the highest measured negative sample, respectively. (b) Results of FSNIA for 2 randomly chosen HIV negative, HBV positive/HIV negative and HCV positive/HIV negative samples respectively in comparison with the intensity of the lowest positive tested sample and blank. The blue and black bars indicate the intensity of the HIV positive sample and the blank, while the red, green and yellow indicate HIV negative, HBV positive/HIV negative and HCV positive/HIV negative samples respectively. 
Table 6 Results of clinical serum analysis which show the high specificity of FSNIA

\begin{tabular}{lllll}
\hline S. no & Sample type & $\begin{array}{l}\text { No. of } \\
\text { samples }\end{array}$ & $\begin{array}{l}\text { No. of samples tested } \\
\text { to be HIV positive }\end{array}$ & $\begin{array}{l}\text { No. of samples tested } \\
\text { to be HIV negative }\end{array}$ \\
\hline 1 & HIV positive & 50 & 50 & NIL \\
2 & HIV negative & 50 & NIL & 50 \\
3 & HIV negative/HBV positive & 10 & NIL & 10 \\
4 & HIV negative/HCV positive & 10 & NIL & 10
\end{tabular}

plasma samples for cross reactivity. We observed that the signal intensity from these samples were as low as the negative control. The comparison of the signals from different plasma samples is presented in Fig. 10a and b. Thus, we could confirm that the assay is very specific to p 24 antigen and is not prone to cross reactivity effects from other biomolecules. As clearly evident from the Table 6 the FSNIA has very high specificity and low cross reactivity.

Thus, we have successfully demonstrated the detection of picogram level concentration of HIV-1 p24 antigen using FSNIA. Our findings confirm that fluorescent nanoparticle based immunoassays could dramatically increase detection sensitivity and have applications in improved diagnosis and point-of-care use. Due to high specificity of streptavidin conjugated silver nanoparticles which have been confirmed by the in silico studies, FSNIA could be developed into a universal labeling technology by replacing capture and detection antibodies for detection of various other antigens. There is no need for specific training of the technicians to handle FSNIA as it is similar to traditional ELISA which is widely practiced across various laboratories and clinics. Upon further optimization and simplification, this could be developed into a rapid and ultrasensitive testing platform for clinical diagnosis and laboratory research in resource limited settings.

\section{Conclusion}

Our work has shown the use of fluorescent silver nanoparticles in infectious disease assay development can result in enhanced assay sensitivity. Although there are similar assays, this assay is capable of detecting HIV p24 antigen in the $\mathrm{pg} \mathrm{mL}^{-1}$ range which will be useful in detecting early HIV infection. The findings described in this paper are important for those developing highly sensitive assays for the estimation of HIV incidence and detection of acute infection cases as part of the strategy towards an AIDS-free generation. This highly sensitive p24 assay can also be adapted to microfluidic platforms and be made available as point of care technology which can help improve blood safety by reducing the antibody negative window period in blood donors in resource limited settings where nucleic acid testing is not practical or feasible.

\section{Disclaimer}

The findings and conclusions in this report are those of the authors and do not necessarily represent the views of the Food and Drug Administration, U.S. Department of Health and Human Services.

\section{Statement of informed consent}

The authors declare that all the experiments that were performed are in compliance with the guidelines of the Institutional Ethics Committee (IEC) of Sri Sathya Sai Institute of Higher Learning, Prasanthi Nilayam. The study was approved by the IEC under the study id SSSIHL/IEC/PSN/BS/2012/01. The plasma samples used in the study were obtained from the patients with their informed consent.

\section{Acknowledgements}

All authors are grateful to Bhagawan Sri Sathya Sai Baba for his constant inspiration and guidance. Aditya Kurdekar thanks DST for their support through the DST-INSPIRE Fellowship program, Ministry of Science and Technology, Government of India. L. A. Avinash Chunduri acknowledges UGC, Government of India for BSR fellowship. The authors thank the Sri Sathya Sai Institute of Higher Medical Sciences for providing us the plasma samples for clinical analysis. They also wish to acknowledge with gratitude Dr B. K. Panigrahi for providing the TEM facility for characterization.

\section{References}

1 Infectious diseases: Global Killers [Internet], 2016 [cited 2016 Sep 9], Available from: http://needtoknow.nas.edu/id/ threats/global-killers/.

2 S. T. Sanjay, G. Fu, M. Dou, F. Xu, R. Liu, H. Qi, et al., Biomarker detection for disease diagnosis using costeffective microfluidic platforms, Analyst, 2015, 140(21), 7062-7081.

3 AIDS FACT SHEET 2016 (Internet), 2016 [cited 2016 Sep 9], available from: http://www.unaids.org/en/resources/factsheet.

4 WHO HIV/AIDS Fact sheet [Internet], 2016 [cited 2016 Jan 1], available from: http:/www.who.int/mediacentre/factsheets/ fs360/en/.

5 M. Février, K. Dorgham and A. Rebollo, CD4+ T Cell Depletion in Human Immunodeficiency Virus (HIV) Infection: Role of Apoptosis, Viruses, 2011, 3(12), 586-612.

6 R. D. Moore and R. E. Chaisson, Natural history of HIV infection in the era of combination antiretroviral therapy, AIDS, 1999, 13(14), 1933-1942. 
7 J. Hurst, M. Hoffmann, M. Pace, J. P. Williams, J. Thornhill, E. Hamlyn, et al., Immunological biomarkers predict HIV-1 viral rebound after treatment interruption, Nat. Commun., 2015, 6, 8495.

8 J. D. Stekler, P. D. Swenson, R. W. Coombs, J. Dragavon, K. K. Thomas, C. A. Brennan, et al., HIV Testing in a HighIncidence Population: Is Antibody Testing Alone Good Enough?, Clin. Infect. Dis., 2009, 49(3), 444-453.

9 F. Oehlenschläger, P. Schwille and M. Eigen, Detection of HIV-1 RNA by nucleic acid sequence-based amplification combined with fluorescence correlation spectroscopy, Proc. Natl. Acad. Sci. U. S. A., 1996, 93(23), 12811-12816.

10 C. D. Pilcher, K. A. Christopoulos and M. Golden, Public health rationale for rapid nucleic acid or p24 antigen tests for HIV, J. Infect. Dis., 2010, 201(1), S7-S15.

11 R. Hans and N. Marwaha, Nucleic acid testing-benefits and constraints, Asian J. Transfus. Sci., 2014, 8(1), 2.

12 S. Tang, J. Zhao, J. J. Storhoff, P. J. Norris, R. F. Little, R. Yarchoan, et al., Nanoparticle-Based Biobarcode Amplification Assay (BCA) for Sensitive and Early Detection of Human Immunodeficiency Type 1 Capsid (p24) Antigen, JAIDS, J. Acquired Immune Defic. Syndr., 2007, 46(2), 231-237.

13 E. S. Daar, T. Moudgil, R. D. Meyer and D. D. Ho, Transient high levels of viremia in patients with primary human immunodeficiency virus type 1 infection, N. Engl. J. Med., 1991, 324(14), 961-964.

14 S. Laperche, M. Maniez-Montreuil and A. M. Couroucé, Screening tests combined with p24 antigen and anti-HIV antibodies in early detection of HIV-1, Transfusion Clinique et Biologique: Journal de La Societe Francaise de Transfusion Sanguine, 2000, 7(1), 18s-24s.

15 J. M. Lange, D. A. Paul, H. G. Huisman, F. de Wolf, H. van den Berg, R. A. Coutinho, et al., Persistent HIV antigenaemia and decline of HIV core antibodies associated with transition to AIDS, Br. Med. J., 1986, 293(6560), 1459-1462.

16 S. A. Spector, C. Kennedy, J. A. McCutchan, S. A. Bozzette, R. G. Straube, J. D. Connor, et al., The antiviral effect of zidovudine and ribavirin in clinical trials and the use of p24 antigen levels as a virologic marker, J. Infect. Dis., 1989, 159(5), 822-828.

17 E. T. N. Abraham, The use of viral culture and p24 antigen testing to diagnose Human Immunodeficiency virus in neonates, N. Engl. J. Med., 2013, 346(24), 1845-1853.

18 J. Böni, M. Opravil, Z. Tomasik, M. Rothen, L. Bisset, P. J. Grob, et al., Simple monitoring of antiretroviral therapy with a signal-amplification-boosted HIV-1 p24 antigen assay with heat-denatured plasma, AIDS, 1997, 11(6), F47-F52.

19 R. M. Lequin, Enzyme immunoassay (EIA)/enzyme-linked immunosorbent assay (ELISA), Clin. Chem., 2005, 51(12), 2415-2418.

20 S. Pang, J. Smith, D. Onley, J. Reeve, M. Walker and C. Foy, A comparability study of the emerging protein array platforms with established ELISA procedures, J. Immunol. Methods, 2005, 302(1-2), 1-12.
21 G. P. Rai and K. S. Venkateswaran, Limitations and Practical Problems in Enzyme Linked Immunosorbent Assays, Def. Sci. J., 1992, 42(2), 71-84.

22 L.-M. Lei, Y.-S. Wu, N.-Q. Gan and L.-R. Song, An ELISA-like time-resolved fluorescence immunoassay for microcystin detection, Clin. Chim. Acta, 2004, 348(1-2), 177-180.

23 J.-Y. Hou, T.-C. Liu, G.-F. Lin, Z.-X. Li, L.-P. Zou, M. Li, et al., Development of an immunomagnetic bead-based timeresolved fluorescence immunoassay for rapid determination of levels of carcinoembryonic antigen in human serum, Anal. Chim. Acta, 2012, 734, 93-98.

24 T. B. Martins, N. H. Augustine and H. R. Hill, Development of a multiplexed fluorescent immunoassay for the quantitation of antibody responses to group A streptococci, J. Immunol. Methods, 2006, 316(1-2), 97-106.

25 Direct vs indirect immunofluorescence [Internet], [cited 2016 Sep 15], available from: http://www.abcam.com/ secondary-antibodies/direct-vs-indirectimmunofluorescence.

26 K. Murray, Y.-C. Cao, S. Ali and Q. Hanley, Lanthanide doped silica nanoparticles applied to multiplexed immunoassays, Analyst, 2010, 135(8), 2132.

27 Y. Tao, M. Li, J. Ren and X. Qu, Metal nanoclusters: novel probes for diagnostic and therapeutic applications, Chem. Soc. Rev., 2015, 44, 8636-8663.

28 X. Yuan, Z. Luo, Y. Yu, Q. Yao and J. Xie, Luminescent Noble Metal Nanoclusters as an Emerging Optical Probe for Sensor Development, Chem.-Asian J., 2013, 8(5), 858-871.

29 N. Goswami, Q. Yao, Z. Luo, J. Li, T. Chen and J. Xie, Luminescent Metal Nanoclusters with Aggregation-Induced Emission, J. Phys. Chem. Lett., 2016, 7(6), 962-975.

30 C. Biology, L. Shang and G. Ulrich, Metal nanoclusters: Protein corona formation and implications for biological applications, Int. J. Biochem. Cell Biol., 2016, 75, 175-179.

31 G. Doria, J. Conde, B. Veigas, L. Giestas, C. Almeida, M. Assunção, et al., Noble Metal Nanoparticles for Biosensing Applications, Sensors, 2012, 12(2), 1657-1687.

32 M. Swierczewska, G. Liu, S. Lee and X. Chen, High-sensitivity nanosensors for biomarker detection, Chem. Soc. Rev., 2012, 41(7), 2641-2655.

33 R. El-Dessouky, M. Georges and H. M. E. Azzazy Silver Nanostructures: Properties, Synthesis, and Biosensor Applications, in Functional Nanoparticles for Bioanalysis, Nanomedicine, and Bioelectronic Devices Volume 1, 2012, pp. 14-359.

34 S. Oldenburg. Silver Nanoparticles: Properties and Applications [Internet], [cited 2016 Sep 15], available from: http://www.sigmaaldrich.com/materials-science/ nanomaterials/silver-nanoparticles.html.

35 A. Travan, E. Marsich, I. Donati and S. Paoletti, Silver Nanocomposites and Their Biomedical Applications, in Nanotechnologies for the Life Sciences, 2007.

36 P. Dallas, V. K. Sharma and R. Zboril, Silver polymeric nanocomposites as advanced antimicrobial agents: Classification, synthetic paths, applications, and perspectives, Adv. Colloid Interface Sci., 2011, 166(1-2), 119-135. 
37 S. A. Latif-ur-Rahman, S. B. Khan, A. M. Asiri, H. Hussain, C. Han, et al., Synthesis, characterization, and application of $\mathrm{Au}-\mathrm{Ag}$ alloy nanoparticles for the sensing of an environmental toxin, pyrene, J. Appl. Electrochem., 2015, 45(5), 463-472.

38 M. Meena Kumari, J. Jacob and D. Philip, Green synthesis and applications of $\mathrm{Au}-\mathrm{Ag}$ bimetallic nanoparticles, Spectrochim. Acta, Part A, 2015, 137, 185-192.

39 S. Hu, B. Ye, X. Yi, Z. Cao, D. Wu, C. Shen, et al., Dumbbellshaped metallothionein-templated silver nanoclusters with applications in cell imaging and $\mathrm{Hg} 2 \mathrm{p}$ sensing, Elsevier, Talanta, 2016; vol. 155, pp. 272-7.

40 Y. Yuan, K. Huang, M. Chang, C. Qin and S. Zhang, Dual emission fluorescent silver nanoclusters for sensitive detection of the biological coenzyme NAD +/NADH, Anal. Biochem., 2016, 494, 46-48.

41 X. Yuan, M. I. Setyawati, A. S. Tan, C. N. Ong and D. T. Leong, Highly luminescent silver nanoclusters with tunable emissions: cyclic reduction - decomposition synthesis and antimicrobial properties, NPG Asia Mater., 2013, 5(2), e39-8.

42 Z. Parang, A. Keshavarz, S. Farahi, S. M. Elahi, M. Ghoranneviss and S. Parhoodeh, Fluorescence emission spectra of silver and silver/cobalt nanoparticles, Sci. Iran., Trans. A, 2012, 19(3), 943-947.

43 M. Padma, B. Govindh and B. V. Rao, Synthesis \& Characterization of Fluorescent Silver Nanoparticles stabilized by Tinospora Cordifolia leaf Extract-A Green Procedure, Int. J. Eng. Res. Ind. Appl., 2014, 4(9), 100-107.

44 N. Khatoon, R. Ahmad and M. Sardar, Robust and fluorescent silver nanoparticles using Artemisia annua: Biosynthesis, characterization and antibacterial activity, Biochem. Eng. J., 2015, 102, 91-97.

45 L. Shang, S. Dong and G. U. Nienhaus, Ultra-small fluorescent metal nanoclusters: Synthesis and biological applications, Nano Today, 2011 Aug, 6(4), 401-418.

46 F. Qu, Q. Li and J. You, Fluorescent silver nanoclusters capped by polyethyleneimine with different molecular weights: Universal synthesis and application as a temperature sensor, J. Lumin., 2016, 177, 133-138.

$47 \mathrm{~J}$. Xu and C. Wei, The aptamer DNA-templated fluorescence silver nanoclusters: ATP detection and preliminary mechanism investigation, Biosens. Bioelectron., 2016, 422-427.

48 A. Contino, G. Maccarrone, M. Zimbone, R. Reitano, P. Musumeci, L. Calcagno, et al., Tyrosine capped silver nanoparticles: A new fluorescent sensor for the quantitative determination of copper (II) and cobalt (II) ions, J. Colloid Interface Sci., 2016, 462, 216-222.

49 C. Wang, L. Xu, Y. Wang, D. Zhang, X. Shi, F. Dong, et al., Fluorescent Silver Nanoclusters as Effective Probes for Highly Selective Detection of Mercury(II) at Parts-perBillion Levels, Chem.-Asian J., 2012, 7(7), 1652-1656.

50 P. Yousefpour, F. Atyabi, R. Dinarvand and E. VasheghaniFarahani, Preparation and comparison of chitosan nanoparticles with different degrees of glutathione thiolation, Daru, 2011, 19(5), 367-375.

51 Molecular Operating Environment [Internet], 2016 [cited 2016 Sep 9], available from: https:/www.chemcomp.com/ MOE-Molecular_Operating_Environment.htm.
52 Hex Protein Docking [Internet], 2013 [cited 2016 Sep 6], available from: http://hex.loria.fr/.

53 D. M. Jameson and J. A. Ross, Fluorescence Polarization/ Anisotropy in Diagnostics and Imaging, Chem. Rev., 2010, 110(5), 2685-2708.

54 L. Maretti, P. S. Billone, Y. Liu, J. C. Scaiano. Facile Photochemical Synthesis and Characterization of Highly Fluorescent Silver Nanoparticles. 2009;(28):13972-13980.

55 K. Jia, P. Wang and X. Liu, Facile synthesis of luminescent silver nanoparticles and fluorescence interactions with blue-emitting polyarylene ether nitrile, J. Mater. Chem. C, 2015, 3(15), 3522-3529.

56 B. A. Ashenfelter, A. Desireddy, S. H. Yau, T. Goodson and T. P. Bigioni, Fluorescence from Molecular Silver Nanoparticles, J. Phys. Chem. C, 2015, 119(35), 20728-20734.

57 S. Pattanayak, A. Priyam and P. Paik, Facile tuning of plasmon bands in hollow silver nanoshells using mild reductant and mild stabilizer, Dalton Trans., 2013, 42(29), 10597-10607.

58 C. Zhu, J. Zhai and S. Dong, Bifunctional fluorescent carbon nanodots: green synthesis via soy milk and application as metal-free electrocatalysts for oxygen reduction, Chem. Commun., 2012, 48(75), 9367.

59 S. K. Balavandy, K. Shameli, D. R. B. A. Biak and Z. Z. Abidin, Stirring time effect of silver nanoparticles prepared in glutathione mediated by green method, Chem. Cent. J., 2014, 8(1), 11.

60 K. Shameli, A. M. Bin, S. D. Jazayeri, S. Sedaghat, P. Shabanzadeh, H. Jahangirian, et al., Synthesis and characterization of polyethylene glycol mediated silver nanoparticles by the green method, Int. J. Mol. Sci., 2012, 13(6), 6639-6650.

61 M. J. E. Fischer, in Amine Coupling Through EDC/NHS: A Practical Approach BT - Surface Plasmon Resonance: Methods and Protocols, ed. J. N. Mol and E. M. J. Fischer, Humana Press, Totowa, NJ, 2010, pp. 55-73.

62 G. T. Hermanson, in Bioconjugate Techniques, Academic Press, Boston, 3rd edn, 2013, p. xvii. available from: http:// www.sciencedirect.com/science/article/pii/ B9780123822390000388.

63 W. A. Lea and A. Simeonov, Fluorescence polarization assays in small molecule screening, Expert Opin. Drug Discovery, 2011, 6(1), 17-32.

64 Fluorescence Polarization [Internet], 2010 [cited $2016 \mathrm{Feb} 9$ ], available from: https://www.thermofisher.com/in/en/home/ references/molecular-probes-the-handbook/technical-notesand-product-highlights/fluorescence-polarization-fp.html.

65 A. Bruno, C. de Lisio and P. Minutolo, Time resolved fluorescence polarization anisotropy of carbonaceous particles produced in combustion systems, Opt. Express, 2005, 13(14), 5393.

66 E. W. Fiebig, D. J. Wright, B. D. Rawal, P. E. Garrett, R. T. Schumacher, L. Peddada, et al., Dynamics of HIV viremia and antibody seroconversion in plasma donors: implications for diagnosis and staging of primary HIV infection, AIDS, 2003, 17(13), 1871-1879. 
67 C. L. Saltzman, J. E. Herzenberg and W. A. Phillips, What nononcologists need to know about MEN IIb, Oncology, 1988, 2(6), 15.

68 A. Shrivastava and V. Gupta, Methods for the determination of limit of detection and limit of quantitation of the analytical methods, Chron. Young Sci., 2011, 2(1), 21.

69 J. Liu, B. Du, P. Zhang, M. Haleyurgirisetty, J. Zhao, V. Ragupathy, et al., Development of a microchip Europium nanoparticle immunoassay for sensitive point-of-care HIV detection, Biosens. Bioelectron., 2014, 61, 177-183.

70 S. Tang and I. Hewlett, Nanoparticle-based immunoassays for sensitive and early detection of HIV-1 capsid (p24) antigen, J. Infect. Dis., 2010, 201(1), S59-S64.

71 R. A. Dar, N. G. Khare, D. P. Cole, S. P. Karna and A. K. Srivastava, Green synthesis of a silver nanoparticlegraphene oxide composite and its application for $\mathrm{As}(\mathrm{III})$ detection, RSC Adv., 2014, 4(28), 14432.

72 L. Shang and S. Dong, Sensitive detection of cysteine based on fluorescent silver clusters, Biosens. Bioelectron., 2009, 24(6), 1569-1573.

73 T. Endo, K. Kerman, N. Nagatani, H. M. Hiepa, D.-K. Kim, Y. Yonezawa, et al., Multiple Label-Free Detection of Antigen-Antibody Reaction Using Localized Surface Plasmon Resonance-Based Core-Shell Structured
Nanoparticle Layer Nanochip, Anal. Chem., 2006, 78(18), 6465-6475.

74 X. Wang, L. Wu, J. Ren, D. Miyoshi, N. Sugimoto and X. Qu, Label-free colorimetric and quantitative detection of cancer marker protein using noncrosslinking aggregation of $\mathrm{Au} /$ $\mathrm{Ag}$ nanoparticles induced by target-specific peptide probe, Biosens. Bioelectron., 2011, 26(12), 4804-4809.

75 S. Paul, D. Paul, G. R. Fern and A. K. Ray, Surface plasmon resonance imaging detection of silver nanoparticle-tagged immunoglobulin, J. R. Soc., Interface, 2011, 8(61), 1204-1211.

76 Z. Chen, Y. Lei and X. Chen, Immunoassay for serum alphafetoprotein using silver nanoparticles and detection via resonance light scattering, Microchim. Acta, 2012, 179(3-4), 241-248.

77 S. Sun, M. Yang, Y. Kostov and A. Rasooly, ELISA-LOC: labon-a-chip for enzyme-linked immunodetection, Lab Chip, 2010, 10(16), 2093.

78 B. S. Lee, J.-N. Lee, J.-M. Park, J.-G. Lee, S. Kim, Y.-K. Cho, et al., A fully automated immunoassay from whole blood on a disc, Lab Chip, 2009, 9(11), 1548.

79 M. Liu, Z. Wang, S. Zong, R. Zhang, D. Zhu, S. Xu, et al., SERSbased DNA detection in aqueous solutions using oligonucleotide-modified Ag nanoprisms and gold nanoparticles, Anal. Bioanal. Chem., 2013, 405(18), 6131-6136. 